\title{
Self-management of heart failure in dementia and cognitive impairment: a systematic review
}

\author{
Janaka Lovell ${ }^{1 *} \mathbb{D}$, Tony Pham', Samer Q. Noaman², Marie-Claire Davis ${ }^{3}$, Marilyn Johnson ${ }^{4}$ and Joseph E. Ibrahim ${ }^{1}$
}

\begin{abstract}
Background: The cornerstone of effective management in heart failure (HF) is the ability to self-care. Aims include i) To determine factors influencing self-care in $\mathrm{HF}$ patients with cognitive impairment (Cl) and ii) to determine the influence of cognitive domains on self-care in patients with $\mathrm{HF}$ and $\mathrm{Cl}$.

Methods: MEDLINE, CINAHL, EMBASE, EBSCOHost, PsychINFO, ProQuest Research Library, Health Technology Assessment Database, The Cochrane Library, Web of Science and Scopus databases were systematically searched. Original research describing the relationship between cognition and $\mathrm{HF}$ self-care in community-dwelling older persons with dementia/Cl in English, published in a peer-reviewed journal from $1^{\text {st }}$ January(2000)-22 ${ }^{\text {nd }}$ March(2016) was identified. Study and population characteristics, data sources, self-care processes, methods of cognitive assessment, cognitive domains affected, study outcomes, impact of impairment, and other risk factors of self-care impairment were abstracted by two reviewers.

Results: Of 10,688 studies identified, 14 met the inclusion criteria. Patients with HF and Cl ranged from 14 to $73 \%$. Where reported, self-care maintenance adequacy ranged from 50 to 61\%; self-care management adequacy ranged from 14 to $36 \%$ and self-care confidence adequacy ranged from 0 to $44 \%$ on the Self-care of Heart Failure Index (SCHFI). All but one study predicted poor self-care ability according to poor outcome on cognitive testing. Additionally, specific cognitive domain deficits impaired self-care. Subjects with lower cognitive scores were less likely to seek assistance while subjects with depression had poor self-care abilities.

Conclusions: Clinicians must consider the type and severity of impairments in cognitive domains to tailor management. Awareness of depression, self-confidence and support access may modulate self-care ability.
\end{abstract}

Keywords: Aging, Self care, Heart failure, Dementia, Cognitive impairment, Cognitive domains

\section{Background}

Heart failure (HF) is a complex clinical syndrome arising from limited cardiac filling or ejection [1]. HF is a major economic burden estimated to cost the United States healthcare system approximately \$USD 30.7 billion annually $[1,2]$. HF has a prevalence of $1-2 \%$ in the general population however, rises to $\geq 10 \%$ of those above 70 years of age and contributed to one-in-nine deaths in 2009 [3]. With an ageing population, the prevalence of HF is projected to rise, which requires considering the management

\footnotetext{
* Correspondence: janakalovell@gmail.com

${ }^{1}$ Department of Forensic Medicine, Monash University, 65 Kavanagh Street,

Southbank, Victoria 3006, Australia

Full list of author information is available at the end of the article
}

of patients with HF in the context of other comorbid geriatric conditions such as dementia [4].

Dementia (a severe form of cognitive impairment) is expected to double in prevalence every 20 years, reaching an estimated 74.7 million persons worldwide by 2030 [5]. Cognitive impairment (CI) is already commonplace being present in $25-75 \%$ of those with HF [6].

Patient self-care is a cornerstone of effective HF management. Key self-care behaviors in HF comprise adhering to complex medication regimens, ensuring dietary sodium and fluid restrictions, appropriate exercise as well as recognizing, managing, and seeking health care advice when changes in symptoms arise $[7,8]$.

(c) The Author(s). 2019 Open Access This article is distributed under the terms of the Creative Commons Attribution 4.0 International License (http://creativecommons.org/licenses/by/4.0/), which permits unrestricted use, distribution, and 
Self-care in HF is a cognitively demanding process requiring response to cues, decision making, disease knowledge and skills in self-management tasks [6]. The neuropsychological deficits of attention, memory and executive dysfunction observed in HF patients could be related to neuroanatomical regional blood flow reduction and may challenge engagement in appropriate self-care behavior $[9,10]$. Unfortunately, CI and ability to self-care is frequently overlooked, whereby sub-optimal engagement in HF self-care is assumed to be due to poor motivation and/or poor compliance $[6,8]$.

At present there are several proposed self-management programs for patients with HF, however, none benefit morbidity or mortality [11]. The impact of $\mathrm{CI}$ or dementia on participation is unknown due to paucity of data. A previous systematic review identified a significant correlation between mild cognitive impairment (MCI) and self-care in HF among eight of nine studies [6]. However, this only included populations with MCI. The current study is the first to examine self-care in community dwelling older persons with mild to severe CI.

\section{Aim}

This systematic review aims to determine: i) factors influencing self-care in HF patients with dementia/CI ii) whether deficits in specific cognitive domains have a differential influence on HF self-care in patients with a co-morbid dementia/CI.

\section{Methods}

This review was conducted according to the Preferred Reporting Items for Systematic Reviews and Meta-Analyses (PRISMA) (Additional file 1) [12].

\section{Definitions}

In this review, dementia is defined as a significant cognitive decline from baseline performance in one or more of five cognitive domains: complex attention, language, perceptual-motor function, learning and memory and, executive function (Additional file 1: Table S1) with concomitant impairment in independent functioning. $\mathrm{MCI}$ is defined as a non-normal, non-demented cognitive state with decline from baseline performance in one or more of six cognitive domains, where the deficits do not impair independent functioning [13]. Cognitive impairment in this review is defined as a clinical state encompassing any degree of $\mathrm{CI}$ from mild to severe (dementia).

Self-management is defined as the ability of the patient to be an active participant in their treatment where they arereponsible for daily management. Self-management comprises five core skills: problem solving, decision making, resource utilization, interacting with health care providers and, taking action [14]. We also describe domains of self-care identified in the Self Care of Heart Failure
Index (SCHFI) including self-care maintenance (10 items: behavioural adherence to treatment recommendations), self-care management ( 6 items: ability to recognise symptoms and respond appropriately by implementing remedies and determining their effectiveness) and self-care confidence (6 items: confidence to engage with self-care processes) [15].

The definition of HF is from the American Heart Association/American College of Cardiology as a "complex clinical syndrome that can result from any structural or functional cardiac disorder that impairs the ability of the ventricle to fill or eject blood" [1].

\section{Data sources and searches}

The following ten databases were searched on 22 March 2016: MEDLINE, CINAHL, EMBASE, EBSCOHost, PsychINFO, ProQuest Research Library, Health Technology Assessment Database, The Cochrane Library, Web of Science and Scopus.

Key terms describing dementia, an aged population, HF and self-management were identified by JEI and JL (Additional file 1), adapted to each database and used to conduct a systematic search. A bibliographic review of included articles was conducted identify additional relevant studies.

\section{Study selection}

Inclusion criteria comprised original research available in English published in a peer-reviewed journal from 1 January 2000 to 22 March 2016. The study population of interest was community dwelling older persons. Included studies investigated paradigms of self-management in populations who had an established diagnosis of dementia or MCI. Studies exploring the impact of dementia or $\mathrm{MCI}$, and the influence of differentially impaired cognitive domains on self-management in HF persons were included.

Exclusion criteria comprised studies that included populations without $\mathrm{CI}$ or populations without a diagnosis of HF. Studies solely testing the effect of an intervention could have introduced bias and therefore were excluded.

MJ and JL screened results for eligibility by title and abstract. TP and JL then independently applied inclusion and exclusion criteria to the full texts to select studies to be appraised, and final selection was made by consensus between JL, TP and JEI.

\section{Data extraction and quality assessment}

Extracted information consisted of study and population characteristics, data sources, self-care processes, methods of cognitive assessment, cognitive domains affected, study outcomes, impact of impairment, and other risk factors of self-care impairment. Conversion of scales reporting the severity of comorbid conditions was developed. 
Included articles were independently assessed by TP and JL using the National Institutes of Health $(\mathrm{NIH})$ study quality assessment tool and differences were resolved by discussion.

\section{Role of the funding source}

This work was supported by the Australian Government Dementia Training Study Centers, Monash University and Ballarat Health Services. These organizations did not have a role in study selection, quality assessment, data synthesis, or in the writing of the manuscript. The investigators are solely responsible for the content of the review.

\section{Results}

\section{Study and population characteristics}

The combined searches returned 10,688 studies, of which 14 met the inclusion criteria (Additional file 1). Of the 14 studies, just over a third $(n=6)$ of the studies were based in the United States of America (USA), two studies were conducted in each of Sweden and Australia while one study was conducted in each of Korea, Italy, Canada and the Netherlands. All studies $(n=14)$ were published from 2005 onwards (Table 1). Included studies were judged to be of fair $(n=9)$ and good $(n=5)$ quality.

Included studies utilized various measures to ascertain HF self-care including disease knowledge $(n=1)(16]$, The Kansas City Cardiomyopathy Questionnaire (KCCQ) ( $n=1)$ (17], prospective memory $(n=1)$ [18], adherence to prescribed medication and lifestyle regimens $(n=2)[19,20]$, ability to complete activities of daily living (ADLs) and independent activities of daily living (IADLs) $(n=2)[21,22]$, The European Heart Failure Self-Care Behavior Scale (EHFScB-9) $(n=1)[23,24]$ and The SCHFI $(n=6)[9,25-32]$ of which one [31] study also utilized the EHFScB-9 (Table 1).

Study designs were largely cross sectional $(n=10)$. Other designs included prospective cohort studies $(n=$ 2 ) and randomized controlled trials $(n=2)$. Methods of data collection included questionnaires in combination with examination $(n=6)$, face-to-face interview $(n=1)$ or telephone interview $(\mathrm{n}=1)$, face-to-face interview alone $(n=5)$ or interview in combination with examination $(n=1)$. Overall study populations were large, ranging from 30 [33] to 628 [32] participants. Participants were mostly hospital outpatient attendees $(n=10)$ while the remaining participants were from primary care/cardiology clinics $(n=2)$, a mix of hospital inpatients and external sources $(n=1)$ while one study [22] did not identify the setting from which participants were drawn (Table 1).

Most studies had participants with a mean age over 65 years $(n=11)$. Studies comprised predominantly male participants with proportions ranging from 55\% [16] to
98.4\% [20] (Table 1). All studies utilized populations from an urban setting.

The severity of HF for included patients were reported according to the New York Heart Association (NYHA) classification for HF and/or left ventricular ejection fraction (LVEF). Three studies [19, 21, 22] recruited subjects with NYHA class II to IV. Patients in these studies had a mean LVEF of $41 \%$. One study recruited subjects with NYHA classes II and III whereby patients had a mean ejection fraction of $34 \%$ [9]. In studies with HF patients as a subgroup, HF made up 9-59\% of subjects and patients either had NYHA class III or IV [16, 17, 24, 25, 29-32]. In many studies, when reported, measured LVEF ranged from 28 to $51 \%$ [16, 20, 29-32] with one study reporting $90 \%$ of subjects having a LVEF $\leq 45 \%$ [29] and another with $72 \%$ of the study population having a LVEF < 40\% [24].

Twelve studies reported the comorbidity status of their subjects. Where comorbidity scores were convertible to severities (Additional file 1), the reported severity of comorbidities ranged from mild to severe [9, 24, 25, 31]. Mild comorbidity severity was prevalent in $41-82 \%$, moderate severity in $15-30 \%$ and severe severity in $2-$ $36 \%$ of these studies' populations. Commonly reported comorbidities for HF patients in the community comprised hypertension (42\% [16] - 76.9\% [20]), previous myocardial infarction (52\% [21] - 54\% [19]), atrial fibrillation (17\% [30] - 54\% [29]) and diabetes (15\% [30] $53.4 \%$ [20]) (Table 1).

\section{Cognitive impairment}

Assessment of cognition was achieved through a combination of examination $(n=7)$ or interview $(n=6)$, with one study utilizing a telephone interview $(n=1)$ [17] to assess neuropsychological status. Global cognition was assessed in most $(n=11)$ of the appraised studies. Tests used to measure global cognition varied and included Mini Mental State Examination (MMSE) $(n=5)$, Montreal Cognitive Assessment (MoCA) $(n=2)$, Korean version of the MMSE (K-MMSE) $(n=1)$, Addenbrooke's Cognitive Examination $(\mathrm{n}=1)$, St. Louis University Mental Status (SLUMS) Exam $(n=1)$, Probed Recall Memory Test $(n=1)$, Digit Symbol Substitution Test (DSST) $(n=$ $1)$ and Telephone Interviews of Cognitive Testing $(n=1)$ (Table 2).

The number of persons with CI varied throughout the studies, ranging from 21 (14\%) [31] - 73 (73\%) [29]. One study identified 40 (16\%) of the study population to have SLUMS test scores consistent with dementia [20].

With regards to testing of individual cognitive domains, two $[19,20]$ studies tested all five cognitive domains while another three $[9,22,24]$ tested four cognitive domains. One [21] study tested three cognitive domains and two $[30,33]$ tested two cognitive domains. 


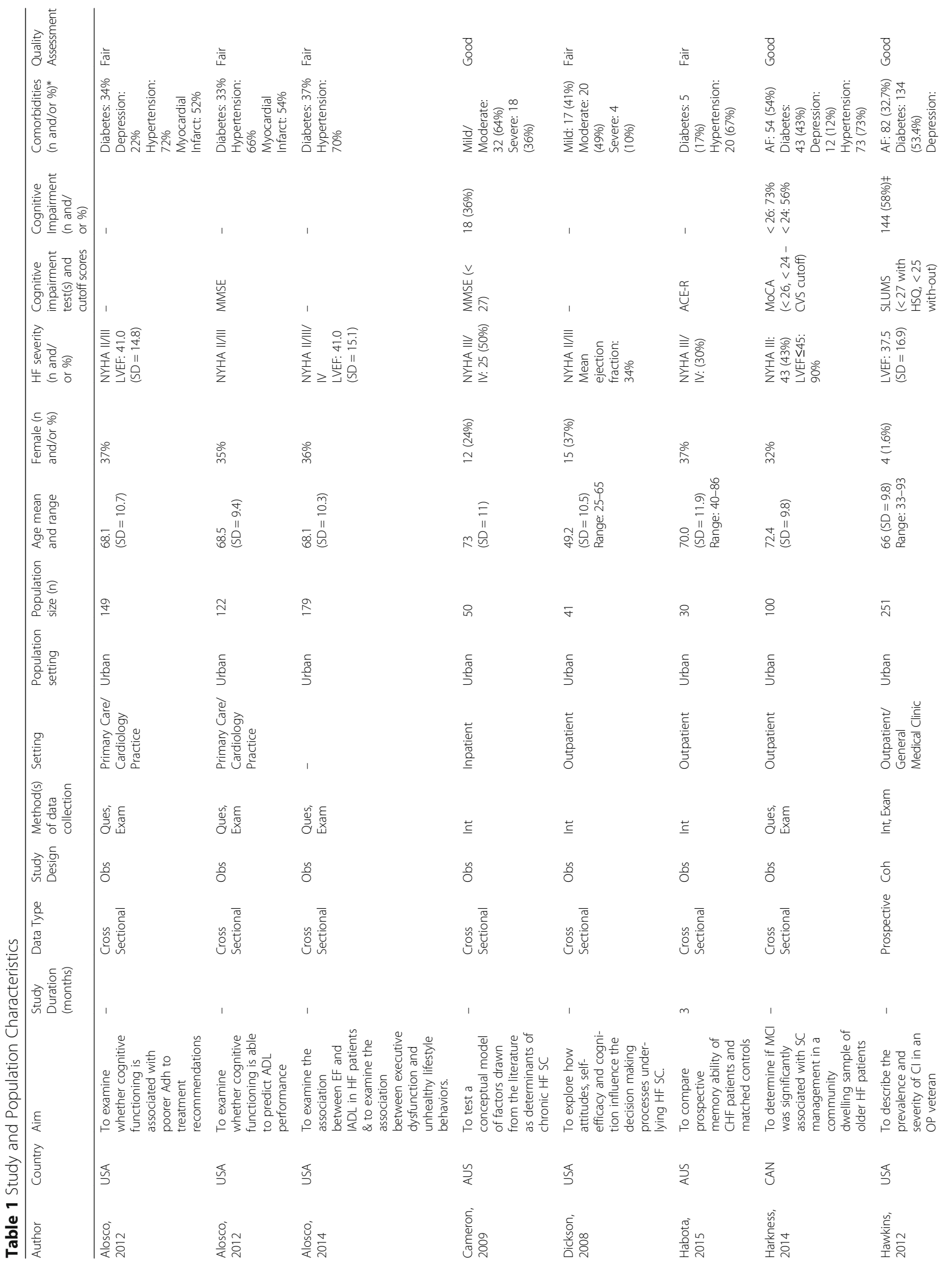




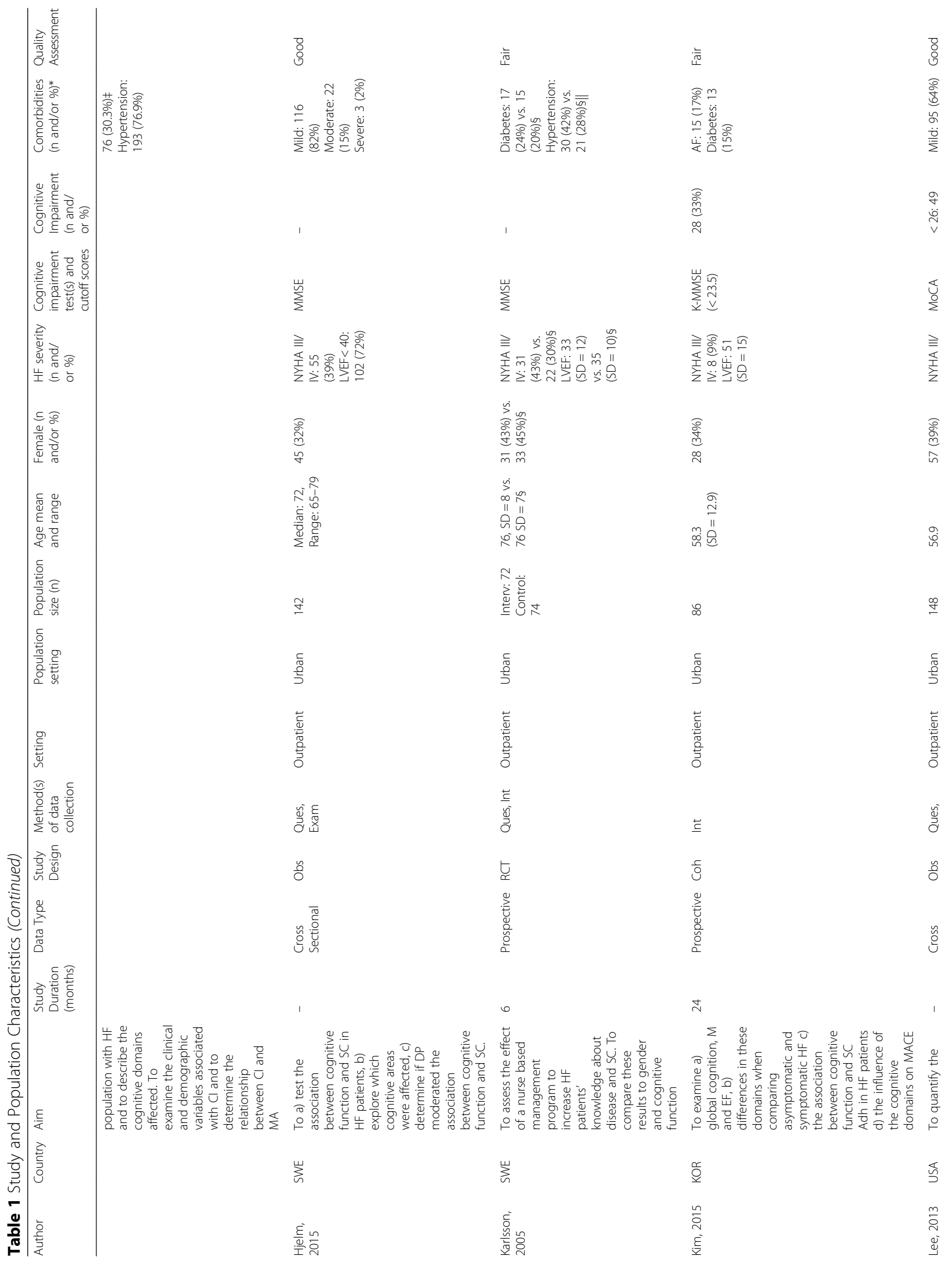




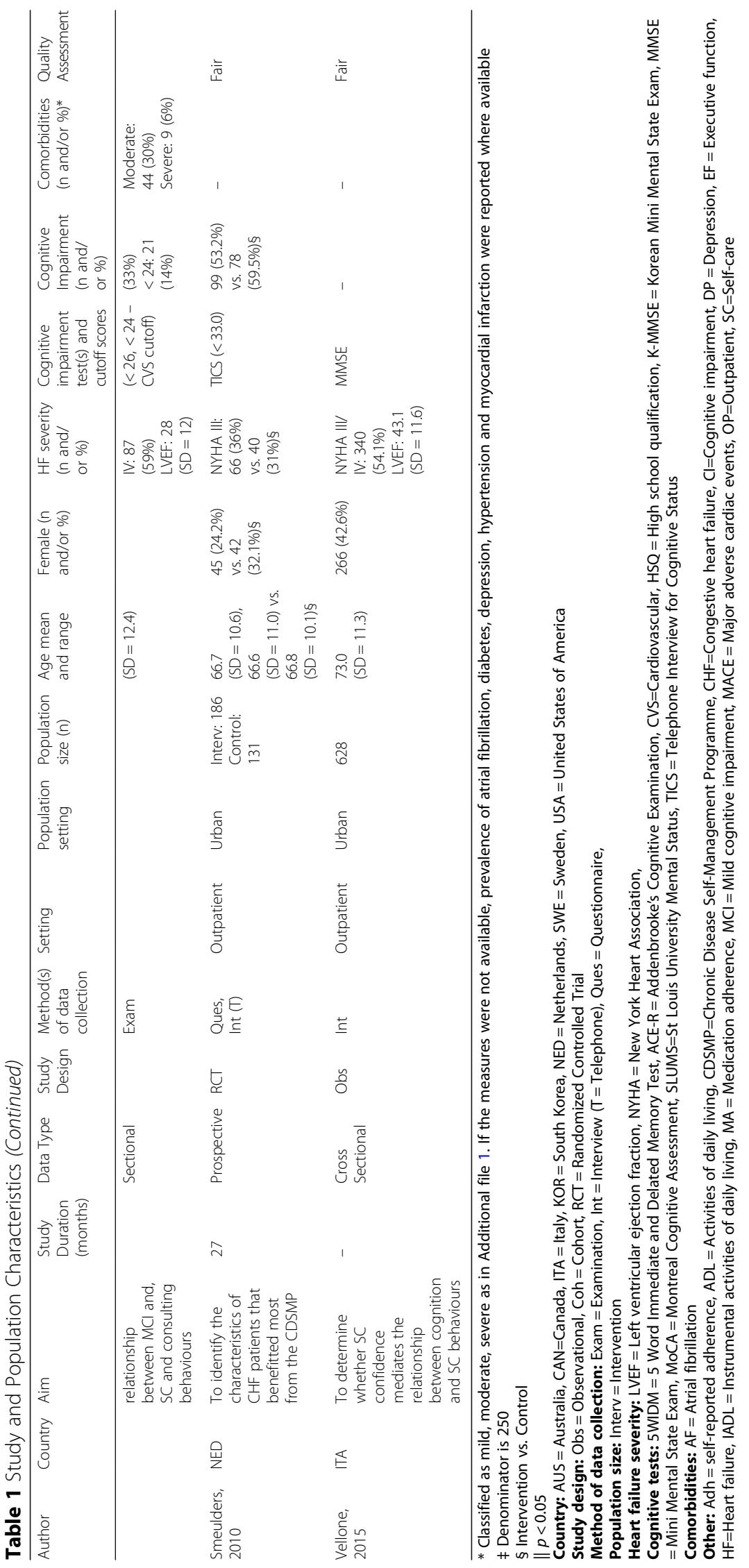




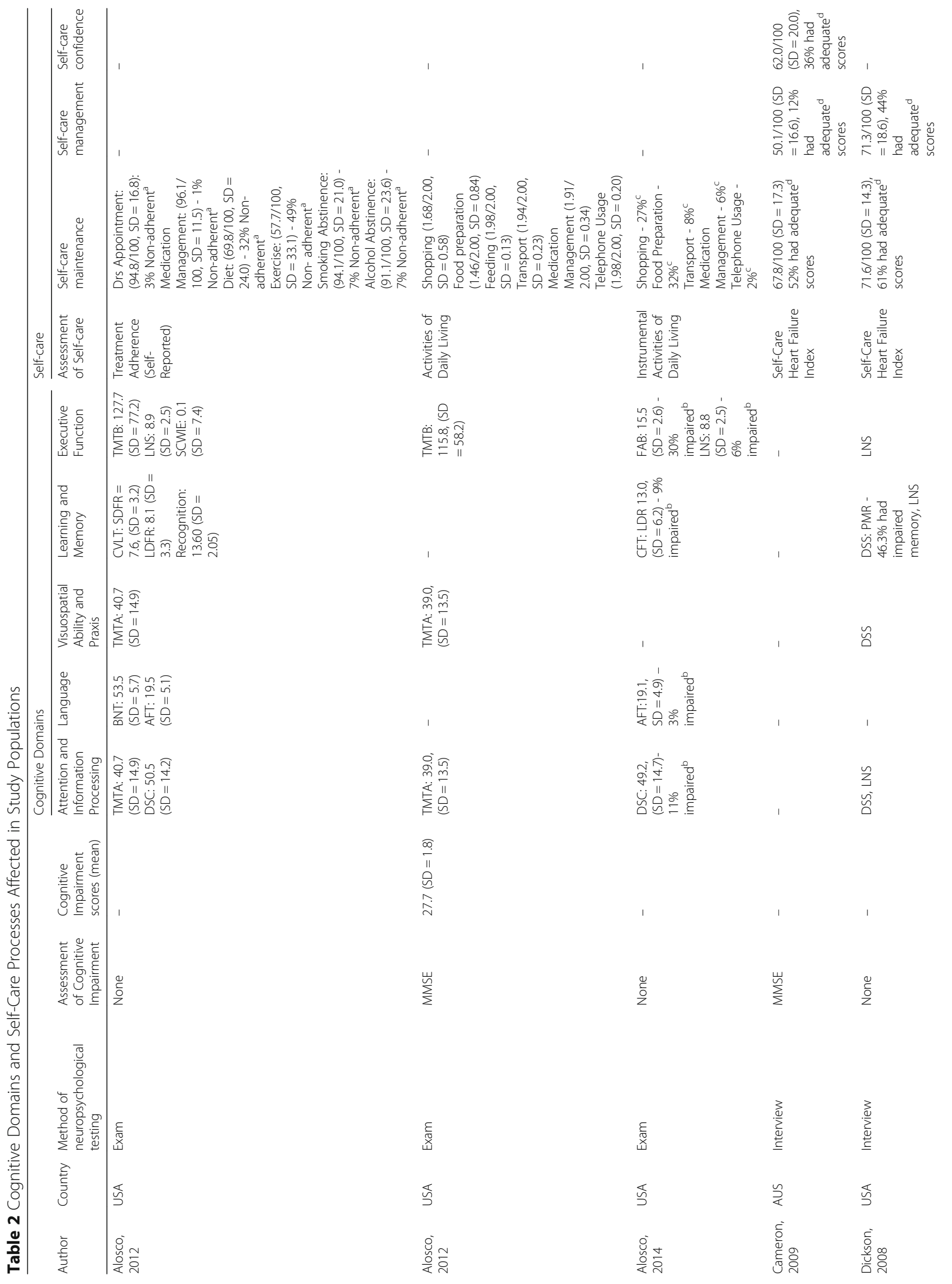




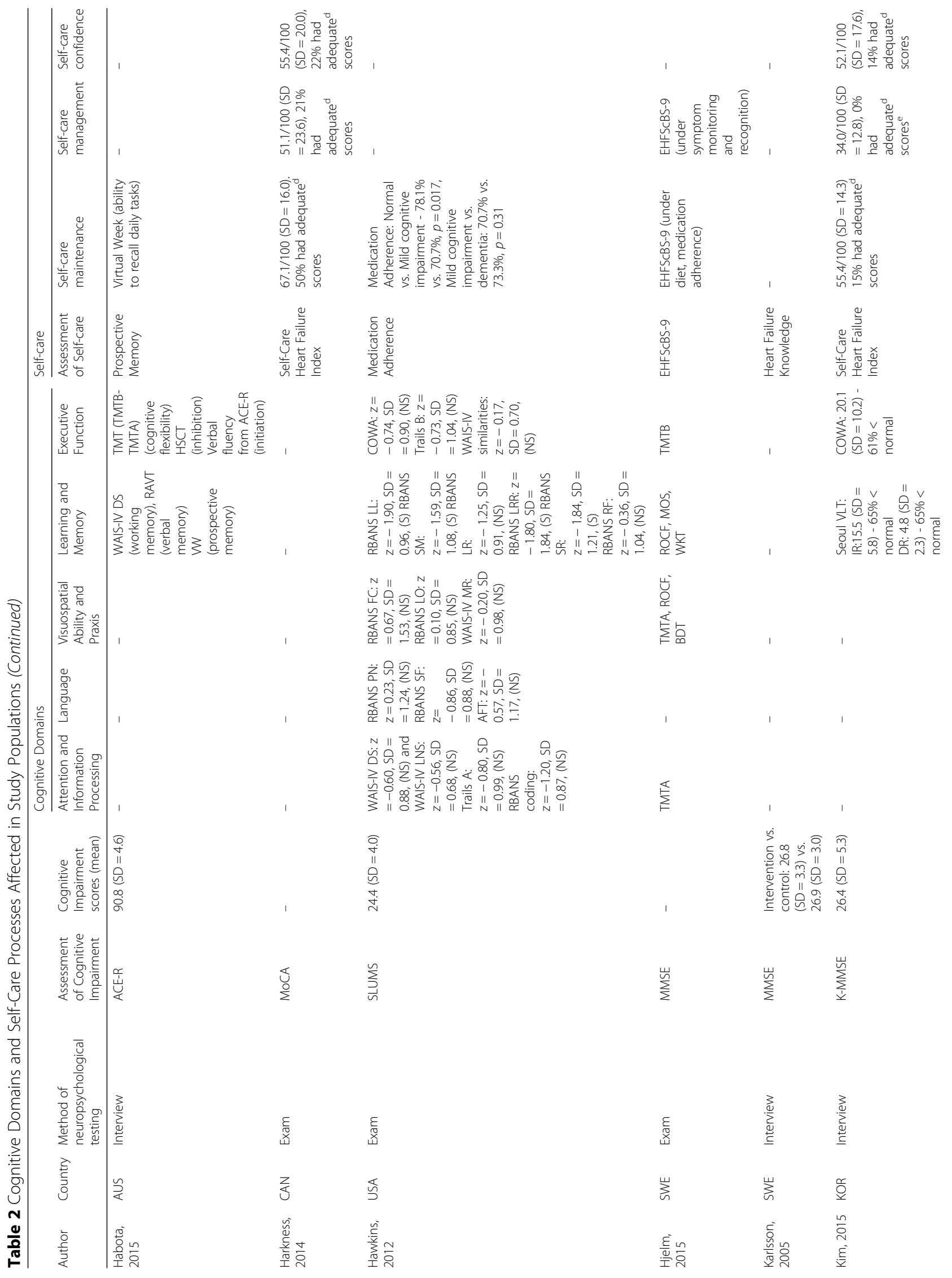




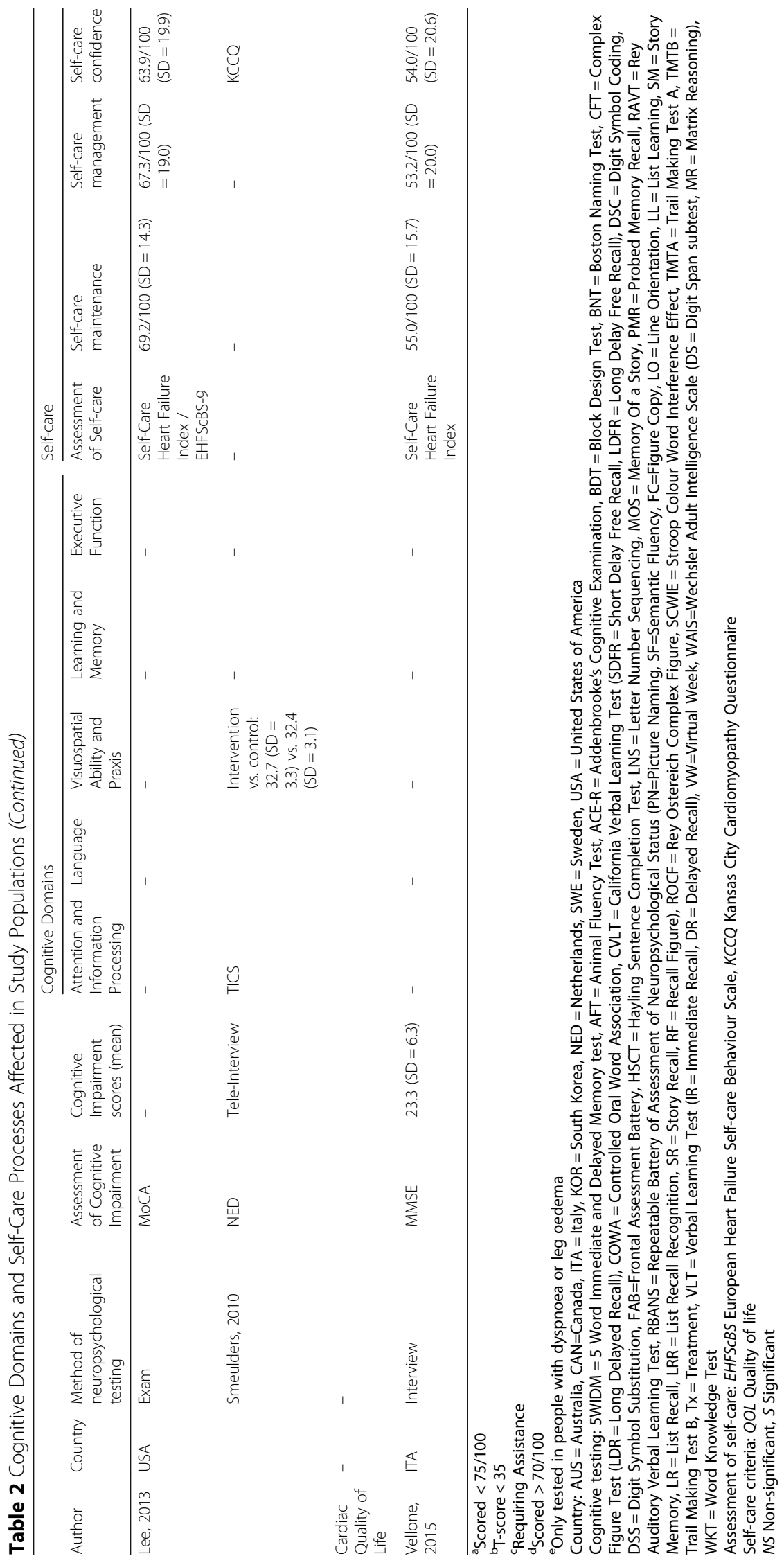


The remaining appraised studies $(n=6)$ assessed global cognition rather than specific cognitive domains.

\section{Self-care \\ Self-care maintenance}

One study [19] examining the influence of cognitive functioning on adherence to treatment recommendations reported non-adherence most commonly arising in diet (32\% non-adherent) and exercise (49\% non-adherent) recommendations. Less common was non-adherence to clinical appointments (3\%) and medication management (1\%). In a separate study [22], the same author found people with impaired executive function commonly required assistance with shopping (27\%) and food preparation (32\%) and less commonly required assistance with transport (8\%), medication management (6\%) and telephone usage (2\%).

Medication adherence in a population of outpatient veterans was impaired in those with MCI when compared to non-CI $(70.7 \%$ vs. $78.1 \% p=0.017)$ subjects [20].

The proportion of patients with adequate self-care maintenance scores on the SCHFI ranged from 50\% [29] to $61 \%$ [9]. $14 \%$ [30] to $36 \%$ [9] of patients had adequate self-care management scores and 0\% [30] to 44\% [9] had adequate self-care confidence scores.

Impact of cognitive impairment and domains on self-care Nine studies explored the impact of CI (either global and/or specific domains) on self-care (Table 3).

\section{Relationship between global cognition and self-care}

At the commencement of an educational intervention program for HF patients, patients with an MMSE <24 had lower scores in self-care and HF knowledge when compared to those who had MMSE scores $>24$ at baseline. However, there was no difference between the two groups after 6 months [16]. Subjects with MoCA scores $<24$ also had worse consulting behavior scores than their counterparts with scores $>24$ [31].

In one study, cognitive function assessed by MMSE score did not significantly predict self-care ability despite contributing to detection of variance in domains of care in the authors' model [25].

In contrast, Dickson and colleagues [9] demonstrated a significant association of CI (as determined by a DSST score less than <27) [26] with improved self-management and maintenance scores. Further, MoCA scores were significant for predicting self-care management abilities with subjects scoring $<26$ being less likely to call a doctor or nurse for disease management guidance [29]. Potentially impacting self-care, subjects with a history of major adverse cardiac events had lower K-MMSE scores compared to those who were event free [30].
A summary of the influence of specific cognitive domains on self-care is presented in Table 3.

\section{Other risk factors for self-care impairment}

Other factors related to impairment in self-care were investigated in five studies $(n=5)$ (Table 3 ).

History of myocardial infarction was found to be protective for overall adherence to medication [19]. Additionally, male gender and having a comorbid diagnosis of depression or diabetes was predictive of lower IADL scores [22]. Furthermore, severe (NYHA) grades of HF were associated with reduced self-care management.

Cameron et al. [25] identified potential factors associated with each of the three domains of self-care. Better self-care maintenance was predicted by greater age and presence of a moderate to severe comorbidity. Improved self-care management was associated with presence of a significant comorbidity and high self-care confidence Finally, poor self-care management was related to male gender. This study only included 50 subjects of which $n=18$ had a MMSE $<27$ so results should be interpreted with caution.

\section{Discussion}

The impact of $\mathrm{CI}$ in patients with HF is significant, contributing to poor engagement in self-care leading to worse health outcomes and increased mortality. By elucidating the relationship between impairment in specific cognitive domains, self-care as well as identifying factors that may modulate self-care abilities, clinicians may tailor management accordingly. Barring patients with $\mathrm{CI}$ from participating in their own management is simplistic, disrespectful and may be counterproductive, increasing dependence and caregiver stress [14, 34, 35].

\section{Statement of key findings}

Poor cognition in patients with HF is well recognized and considered to be a result of chronic cerebral hypo-perfusion, leading to ischemic damage and subsequent functional alteration [10]. Optimal self-care is an important non-pharmacological aspect of HF management that stabilizes symptoms and improves health outcomes.

To our knowledge, this is the only systematic review to consider the role of $\mathrm{CI}$, from the spectrum of mild CI to dementia, on self-care in community dwelling adults with HF. Throughout the appraised articles there was heterogeneity in the methods used to assess cognition and self-care. As a consequence, the results of appraised studies could not be analysed in an aggregate form.

\section{Self-care domain adequacy in cognitive impairment}

When assessment was based on the SCHFI self-care assessment tool, self-care management and self-care 
Table 3 Study Outcomes, Impact of Cognitive Impairment, Relevant Risk Factors and Suggested Strategies

\begin{tabular}{lll}
\hline Author & Study Outcome $(\mathrm{n}$ and/or \%) & $\begin{array}{l}\text { Impact of Cognitive Impairment } \\
\text { on Self- care }\end{array}$ \\
\hline Alosco, 2012 & Adherence Score: & $\downarrow$ Attention: $\downarrow$ Doctor's Appointment \\
& $84.0 / 100 \mathrm{SD}=11.6$. & Adherence $(\mathrm{r}(138)=0.29, p<0.001)$ \\
& $\& \downarrow$ wedication Management \\
& & $(\mathrm{r}(138)=0.25, p<0.01)$. \\
& $\downarrow$ Executive Function: $\downarrow$ Doctor's \\
& Appointment Adherence $(\mathrm{r}(138)=$ \\
& $0.29, p<0.001)$. \\
& $\downarrow$ Language: $\downarrow$ Medication \\
& Management $(r(138)=0.28$, \\
& $p<0.01) \& \downarrow$ Diet Adherence $(r(138)$ \\
& $=0.17, p=0.04)$
\end{tabular}

Alosco, 2012 Activities of daily living score: $25.2 / 28(S D=3.4)$

Alosco, $2014 \quad$ Instrumental activities of daily living score: 13.5/16 $(S D=2.9)$. $\downarrow$ Executive function: $\uparrow$ Cigarette smoking $(r(167)=-0.20, p=0.01)$

Cameron, 2009 Self-care maintenance: 67.8/100 $\mathrm{SD}=17.3$ Self-care management: 50.1/100, $\mathrm{SD}=16.6$ Self-care confidence: $62.0 / 100$, $\mathrm{SD}=20.0$

The 7 variable mode $^{\mathrm{b}}=39 \%$ of variance in Self-care maintenance \& $38 \%$ of variance in Self-care management
ITMTA performance (Attention,

Visuospatial): $\downarrow$ Medication

Management

$(ß=-0.24, p<0.05)$

$\downarrow M M S E: \downarrow$ Driving scores $(B=-0.25$, $p<0.001)$

$\downarrow$ Executive function: $\downarrow$ Instrumental activities of daily living performance $(B=0.24, p=0.01)$ $=0.16, p<0.03) \&$ medication management $(r(167)=0.15$ $p=0.05$ ).

$\downarrow$ Executive function associated with $\uparrow$ cigarette use $(r(167)=-0.20$ $p=0.01$ ).

Cognitive function non-significant factor in 7 variable model however when omitted from the model, 6 variables explain $\downarrow 4 \%$ of the variance in self-care maintenance (39\% - > 35\%). This was also seen in self-care management (38 -> $34 \%)$

Care Impairment

Myocardial infarction is

associated with $\uparrow$ treatment

adherence ( $B=0.23$,

$p=0.01$ )
Suggested Strategies/

Intervention

Cognitive function

assessment can influence the course of heart failure management Especially food preparation ( $r(167)$

Male $(B=-0.29, p<0.001)$,

Diabetes $(\beta=$

$-0.19, p=0.01)$

Depression $(B=-0.15$,

$p=0.04)$ associated

with $\downarrow$ instrumental activities

of daily living performance

Self-care maintenance:

$\uparrow$ Age: $\uparrow$ Self-care

maintenance $(B=0.51$,

$p<0.01$ );

Significant comorbidity

(CCSI $\geq 4)$ : $\uparrow$ Self-care

maintenance $(B=0.34$,

$p=0.02$ ).

Self-care management:

Male: $\downarrow$ Self-care

management $(B=-0.33$,

$p=0.02$ );

No significant comorbidity

$(C C S \mid<4)(B=0.33, p=0.03)$ :

$\uparrow$ Self-care management;

Depression: $\uparrow$ Self-care

management $(B=0.32$,

$p=0.04)$;

$\downarrow$ Self-care confidence: $\downarrow$ Selfcare management $(B=0.39$, $p<0.01)$

Dickson, 2008 Self-care management: (71.3/100, $\mathrm{SD}=18.6) 44 \%$ had adequate scores (>70).

care management and $\uparrow$ self-care $\begin{array}{ll}\text { scores }(>70) \text {. } & \text { care management and } \uparrow \text { self-care } \\ \text { Self-care maintenance: }(71.6 / 99.99, & \text { maintenance scores vs. ' } \downarrow \text { vigilant' }\end{array}$ $\mathrm{SD}=14.3) 61 \%$ had adequate scores $(>70)$.

Significant difference in self-care maintenance and self-care management between expert ${ }^{c}$, novice $^{\mathrm{d}}$ and inconsistent groups ${ }^{\mathrm{e}}$ $(p=0.001)$.

Habota, 2015 Trend: Congestive heart failure (mean $=0.5, \mathrm{SD}=0.4$ ) performing $\downarrow$ than controls (mean $=0.6$,

$\mathrm{SD}=0.3$.

For the proportion of tasks
'Inconsistent' group: Cognitive impairment (DSS < 26) had $\uparrow$ selfand 'discordant' ( $p=0.02$ to 0.03 ). screening for modifiable and non-modifiable factors can $\uparrow$ health outcomes and follow up strategies
Regular screening of cognitive impairment can provide information about self-care behaviors

Technological devices which promote executive function could improve self-care outcomes.

Developing self-efficacy in difficult situations will lead to (+) self-care decisions and help overcome temptations which leads to $\uparrow$ self-care confidence

$\uparrow$ Self-care adherence may need to include prospective memory training 
Table 3 Study Outcomes, Impact of Cognitive Impairment, Relevant Risk Factors and Suggested Strategies (Continued)

\begin{tabular}{|c|c|c|c|c|}
\hline Author & Study Outcome ( $\mathrm{n}$ and/or \%) & $\begin{array}{l}\text { Impact of Cognitive Impairment } \\
\text { on Self- care }\end{array}$ & $\begin{array}{l}\text { Other Risk Factors for Self- } \\
\text { Care Impairment }\end{array}$ & $\begin{array}{l}\text { Suggested Strategies/ } \\
\text { Intervention }\end{array}$ \\
\hline & $\begin{array}{l}\text { missed, there was a main effect } \\
\text { of group }(F(1,57)=4.52, p=0.038 \text {, } \\
\left.n p^{2}=0.07\right) \text {. } \\
\text { The congestive heart failure } \\
\text { group (mean }=0.26, S D=0.31 \text { ) } \\
\text { missed } \uparrow \text { tasks than the control } \\
\text { group (mean }=0.16, S D=0.21 \text { ). }\end{array}$ & & & \\
\hline Harkness, 2014 & $\begin{array}{l}\text { Self-care management: MoCA } \\
\text { score }<26 \text { (mild cognitive } \\
\text { impairment) scored significantly } \downarrow \\
\text { vs. scores } \geq 26(48.1 / 100(S D=24) \\
\text { vs. } 59.3 / 100(S D=22), p=0.035) \text {. } \\
\text { Also observed with the MoCA } \\
\text { cutoff at }<24 \text { and } \geq 24,(45.6 / 100 \\
(S D=23) \text { vs. } 58.1 / 100(S D=23), \\
p=0.008)\end{array}$ & $\begin{array}{l}\text { MoCA was a significant factor (B= } \\
1.784, p=0.001) \text { in model for self- } \\
\text { care management }(F(3,96)=7.04 \text {, } \\
p<0.001) \text {. } \\
\text { Mild cognitively impaired } \\
\text { participants (both }<26 \text { and }<24) \\
\text { were } \downarrow \text { likely to call a doctor or } \\
\text { nurse for guidance }(52 \% \text { vs. } 89 \% \text {, } \\
p=0.001,46 \% \text { vs. } 82 \%, p<0.001 \\
\text { respectively) }\end{array}$ & - & $\begin{array}{l}\text { Formal screening for mild } \\
\text { cognitive impairment can } \\
\text { help to identify individuals } \\
\text { who are risk of self-care } \\
\text { management difficulty and } \\
\text { of delaying assistance from } \\
\text { a health care provider. Ex- } \\
\text { periential learning and prob- } \\
\text { lem solving skills are } \\
\text { important for the elderly. }\end{array}$ \\
\hline Hawkins, 2012 & $\begin{array}{l}\text { Cognitive impairment present in } \\
57.6 \% \text {. Verbal learning, immediate } \\
\text { memory, and delayed verbal } \\
\text { memory were found to be } \\
\text { impaired. } \\
\text { Associations with cognitive } \\
\text { impairment: Age }(\mathrm{OR}=1.42, \\
95 \% \mathrm{Cl}=1.03-1.95, p=0.031) ; \\
\text { African American race }(\mathrm{OR}=3.59 \text {, } \\
95 \% \mathrm{Cl}=1.90-6.81, p<0.01) ; \\
\text { Depression }(\mathrm{OR}=1.43,95 \% \mathrm{Cl}= \\
1.12-1.83, p=0.004) ; \\
\text { Former alcohol use }(\mathrm{OR}=2.13 \text {, } \\
95 \% \mathrm{Cl}=1.06-4.31, p=0.034) ; \\
\text { missed follow up of pill count } \\
\text { (OR=2.03, } 95 \% \mathrm{Cl}=1.20-3.45 \\
p=0.009) \text {. } \\
\text { Medication adherence } \uparrow \text { in } \\
\text { participants with no Cl vs. } \mathrm{MCl} \\
\text { (78.1\% vs. } 70.7 \%, p=0.017)\end{array}$ & - & - & $\begin{array}{l}\text { Screen patients for cognitive } \\
\text { impairment and depression. } \\
\text { Interventions should look to } \\
\text { target verbal learning, verbal } \\
\text { memory and delayed verbal } \\
\text { memory }\end{array}$ \\
\hline Hjelm, 2015 & $\begin{array}{l}\text { Psychomotor speed associated } \\
\text { with self-care }(B=-0.09, \mathrm{t}(99)= \\
-2.92, p=0.004) \text {. No moderating } \\
\text { effects of depression were found. }\end{array}$ & - & - & $\begin{array}{l}\text { Screening for impaired } \\
\text { psychomotor speed to } \\
\text { identify patients in need of } \\
\text { individualized self-care } \\
\text { teaching. }\end{array}$ \\
\hline Karlsson, 2005 & $\begin{array}{l}\text { Intervention group did not have } \\
\uparrow \text { knowledge vs. control group } \\
\text { after } 6 \text { months }(13.2(\mathrm{SD}=3.4) \text { vs. } \\
12.7(\mathrm{SD}=3.3) \text {, NS). }\end{array}$ & $\begin{array}{l}\text { MMSE }<24 \text { had } \downarrow \text { scores in self- } \\
\text { care and heart failure knowledge } \\
\text { vs. MMSE } \geq 24(10.1(S D=3.6) \text { vs. } \\
12.8(S D=3.4), p<0.01) \text { at } \\
\text { baseline. } \\
\text { There was no difference between } \\
\text { the } 2 \text { groups after } 6 \text { months. }\end{array}$ & - & $\begin{array}{l}\text { Education of patients should } \\
\text { be given individually and } \\
\text { given through different } \\
\text { means (verbal, written, } \\
\text { electronic) }\end{array}$ \\
\hline Kim, 2015 & $\begin{array}{l}\text { NYHA I (asymptomatic) vs. } \\
\text { NYHA } \geq I \text { (symptomatic): Global } \\
\text { function }(27.8(S D=2.5) \text { vs. } 24.9 \\
(S D=4.4), p=0.001), \text { Memory } \\
(17.5(S D=5.7) \text { vs. } 13.4(S D=5.2) \text {, } \\
p=0.001), \text { executive function } \\
(23.4(S D=9.8) \text { vs. } 16.9(S D=9.6) \text {, } \\
p=0.002) \\
\text { Also observed in self-care confi- } \\
\text { dence }(57.0(S D=17.4) \text { vs. } 53.2 \\
(S D=13.8), p=0.009) \text {. }\end{array}$ & $\begin{array}{l}\text { Delayed recall memory predicted } \\
\text { self-care confidence adequacy (OR } \\
=1.41,95 \% \mathrm{Cl}=1.03-1.92, p= \\
0.033) \text {. MACE had } \downarrow \text { K-MMSE scores } \\
\text { vs. 'event free' ( } 23.9 \text { vs. } 27.1, \mathrm{t}= \\
2.30, p=0.024) .\end{array}$ & - & - \\
\hline Lee, 2013 & $\begin{array}{l}\text { MoCA }<26 \text { : } \downarrow \text { Self-care } \\
\text { management scores vs. MoCA } \\
\geq 26 \text { (difference }=8.2 \%, S D=3.8 \% \\
p=0.043 \text { ). }\end{array}$ & $\begin{array}{l}\text { MoCA }<24 \text { had worse adjusted } \\
\text { consulting behavior scores } \\
\text { (difference }=50.7 \%, S D=15.3 \% \text {, } \\
p=0.001 \text { ) }\end{array}$ & - & $\begin{array}{l}\text { Cognition should be } \\
\text { assessed with clinically } \\
\text { appropriate tools (e.g. } \\
\text { employing the MoCA cutoff }\end{array}$ \\
\hline
\end{tabular}


Table 3 Study Outcomes, Impact of Cognitive Impairment, Relevant Risk Factors and Suggested Strategies (Continued)

\begin{tabular}{|c|c|c|c|c|}
\hline Author & Study Outcome (n and/or \%) & $\begin{array}{l}\text { Impact of Cognitive Impairment } \\
\text { on Self- care }\end{array}$ & $\begin{array}{l}\text { Other Risk Factors for Self- } \\
\text { Care Impairment }\end{array}$ & $\begin{array}{l}\text { Suggested Strategies/ } \\
\text { Intervention }\end{array}$ \\
\hline & $\begin{array}{l}\text { MoCA }<24: \downarrow \text { Adjusted self-care } \\
\text { maintenance (difference }=13.8 \% \text {, } \\
\mathrm{SD}=5.4 \%, p=0.014 \text { ) and self-care } \\
\text { management scores (difference }= \\
21.4 \%, \mathrm{SD}=8.0 \%, p=0.014 \text { ) vs. } \\
\text { participants with scores } \geq 24 \text {. } \\
\text { MoCA }<24 \text { also had significantly } \\
\text { lower EHFScBS scores (difference } \\
=38.3 \%, \mathrm{SD}=11.2 \%, p=0.001 \text { ) }\end{array}$ & & & $\begin{array}{l}\text { of }<24 \text { ). } \\
\text { Systematic screening for } \\
\text { mild cognitive impairment }\end{array}$ \\
\hline $\begin{array}{l}\text { Smeulders, } \\
2010\end{array}$ & $\begin{array}{l}\text { Participants with TICS }<33 \text { had } \\
\text { worse cardiac quality of life at } \\
\text { first follow up (Difference }=-6.3 \text {, } \\
p=0.027,95 \% C l=-11.9 \text { to }-0.7 \text { ). } \\
\text { Scores were not significantly } \\
\text { different at } 6 \text { and } 12 \text { months. }\end{array}$ & - & - & $\begin{array}{l}\text { Encourage patients with } \\
\downarrow \text { education levels to } \\
\text { participate in CDSMP classes. } \\
\text { Tailor CDSMP to cognitively } \\
\text { impaired patients. Screen for } \\
\text { cognitive status and } \\
\text { education level. }\end{array}$ \\
\hline Vellone, 2015 & $\begin{array}{l}\text { MMSE score influenced self-care } \\
\text { maintenance and self-care man- } \\
\text { agement through the mediating } \\
\text { effects of self-care confidence } \\
\text { MMSE predicted self-care confi- } \\
\text { dence. Self-care confidence pre- } \\
\text { dicted self-care management and } \\
\text { self-care maintenance. } \\
\text { Cognition does not have a direct } \\
\text { effect on self-care. It only influ- } \\
\text { enced self-care through its effect } \\
\text { on self-care confidence }\end{array}$ & - & $\begin{array}{l}\text { Self-care maintenance } \\
\uparrow \text { Illness duration predicted } \\
\uparrow \text { self-care maintenance } \\
\text { Self-care management: } \\
\uparrow N Y H A \text { class predicted } \\
\downarrow \text { self-care management } \\
\text { Self-care confidence: } \\
\downarrow \text { Age and female gender } \\
\text { predicted } \uparrow \text { self-care } \\
\text { confidence }\end{array}$ & $\begin{array}{l}\text { Interventions that } \uparrow \text { self-care } \\
\text { confidence may } \uparrow \text { self-care } \\
\text { even in patients with cogni- } \\
\text { tive impairment. Reward pa- } \\
\text { tients for small successes in } \\
\text { their adherence to self-care } \\
\text { behaviors. Introduce patients } \\
\text { to others in the same situ- } \\
\text { ation who are proficient at } \\
\text { self-care. Tell patients that } \\
\text { they are able to be profi- } \\
\text { cient at self-care. Provide } \\
\text { and encourage support for } \\
\text { patients. }\end{array}$ \\
\hline
\end{tabular}

${ }^{\mathrm{a}}$ Scored $<75 / 100$

${ }^{\text {b}} 7$ Variable Model constituents: age, gender, comorbidity, cognitive function, depression, social situation, self-confidence

${ }^{\mathrm{c}}$ Expert $=$ Proficient at heart failure self-care

${ }^{\mathrm{d}}$ Novice $=$ No skill or experience in heart failure self-care

e Inconsistent $=$ Neither expert nor novice

CDSMP=Chronic Disease Self-Management Programme, DSS = Digit Symbol Substitution, EHFScBS = European Heart Failure Self-care Behavior Scale, HFK=Heart failure knowledge, HFP=Heart failure program, MACE = Major Adverse Cardiac Event, MMSE = Mini Mental State Exam, MoCA = Montreal Cognitive Assessment, NYHA $=$ New York Heart Association, TICS $=$ Telephone Interview for Cognitive Status, TMTA = Trail Making Test A, (+) = positive, $\uparrow=$ increased, $\downarrow=$ reduced

confidence adequacy was lacking in CI subjects with self-reported adequacy.

Interestingly, Vellone and colleagues suggest self-care confidence is impaired by poor cognition thus leading to worse self-care behaviours [32]. Dickson and colleagues also found that self-efficacy and positive attitudes towards disease were important in facilitating appropriate or "expert" self-care behaviours [9].

Of note, the proportion of participants with adequate self-care maintenance scores were equal, if not higher in CI subjects compared to those who had inconsistent levels of cognition [9, 29]. MCI subjects had lower medication adherence rates than subjects with no $\mathrm{CI}$, but similar rates to those with increasingly worse CI [20]. This may be attributed to CI persons having strong social support networks and assistance, which has been shown to predict greater adherence to treatment in populations with cardiac disease [36]. Unfortunately, none of the studies appraised analysed the effect of caregivers or spouses on adherence in the population of interest.

\section{Cognitive impairment and lifestyle adherence}

Patients who either had impairments in multiple separate domains or global cognition had poor self-care maintenance abilities. These were namely medication adherence, compliance with lifestyle recommendations or requiring assistance with ADLs [19-22]. The impact of cognition on these aspects of self-care is important as it determines the execution of these key activities. For instance, medication management and driving are inextricably linked to outcomes such as re-hospitalisation or admissions to geriatric units respectively [22].

One proposed theory for impaired self-care ability is that as cognitive decline diminishes so does functional ability with the resulting lessened influence of personal values towards self-care [9, 37]. Specifically, cognitive domains implicated included attention/information processing, executive function, language and finally, 
visuospatial and constructional abilities. Attentional control and executive functioning are domains often impaired in most chronic, systemic diseases [38-40].

Given the published literature [41] it was expected that impaired executive function is linked to inability to self-care. Executive functioning is important as it is related to dis-inhibition, poor self-monitoring, poor organisation and planning and also affects learning and recall efficiency. Impairment in this domain affects the critical need for HF patients to be able to adapt to complex treatment and lifestyle regimens, to recognise and respond to worsening symptoms (e.g. fluid overload, shortness of breath), communicate and seek help in a timely manner, have insight into disease (hence higher rates non-adherence to cigarette smoking) and ability to conduct multiple daily self-management tasks [42, 43]. Therefore, deficits in executive function are known to be associated with a lack of both awareness about worsening symptoms and timely decisions ultimately leading to poorer outcomes, including decompensation and hospitalization [44].

Decline in language function is related to poor literacy, inability to state concerns about disease condition and, poor understanding of instructions and medical advice. All of these, along with executive function decrements may also contribute to worse treatment and lifestyle adherence in those with CI and HF.

If attention and poor concentration are an issue [9] it may distract from execution of certain tasks while impairment in prospective memory may have an adverse impact on engagement in self-care behaviours such as picking up prescriptions from the pharmacist, attending clinical appointments, treatment adherence and daily weighing, all of which are important in HF self-management [33].

Impairments in psychomotor speed may result in poor flexibility in shifting activities and slowing of responses to visual stimuli. These skills are important in learning and conducting multiple daily self-care tasks $[24,43]$.

Consistent with the relationship between $\mathrm{CI}$ and self-care with poor outcomes demonstrated by the majority of appraised studies, Pressler and colleagues reported that along with reduced $\operatorname{LVEF}(\leq 40 \%)$, impairment in global CI, memory, psychomotor speed and executive function were predictors of 12 month all-cause mortality [45].

Symptoms of HF are difficult to interpret even in cognitively intact individuals. This is increasingly difficult in the context of impaired cognitive domains and is compounded by the pathophysiology of HF decompensation where symptoms of fatigue or acute confusion may detract from executing effective self-care actions [46]. Reduced ability to self-care will subsequently lead to worsening symptoms and advanced cardiac dysfunction.

\section{Seeking help}

Subjects with poor MoCA scores were less likely to seek assistance from a medical staff for disease management guidance respectively [29, 31]. Executive function deficits may impair recognition of symptoms and problem-solving, hence these patients delay initiation of self-management and may not recognize when, why or from whom they need to seek assistance. This is further complicated by IADL, language and attention deficits as HF patients may not have the ability to engage in using communication facilities [29].

\section{The effect of depression on self-care}

Psychological status influences self-care behaviors [47] through patient perceived self-efficacy or indirectly, through effects on memory and executive function [48]. In the present review, a diagnosis of depression was found to be predictive of lower IADL abilities and poor self-care management [22, 25].

\section{Education programs}

One study explored the effectiveness of an education program [16]. CI patients had lower scores in self-care and HF knowledge initially compared to non-CI subjects. However, there was no difference in self-care and knowledge after 6 months of the program. This may be due to improvement in cardiac function and hence cognitive function in patients who were receiving acute treatment for HF [49]. However, several studies have also identified that provision of education, treatment and lifestyle instructions alone are not adequate to uphold appropriate self-care behavior [50, 51].

\section{Strengths and limitations}

The current review is extensive, examining the effect of CI on a spectrum of mild-severe, covering literature published from 2000 to March - 2016. We were limited to peer reviewed literature published solely in the English language. Ten of the 14 studies appraised were cross-sectional studies, however, prospective studies may more accurately explore the causal nature between CI and self-care among patients with HF.

A stronger relationship between cognition and self-care may not have been observed due to the use of certain cognitive testing tools which are insensitive to higher order functions. If clinicians choose to screen for dementia with the MMSE, they may possibly fail to detect mild impairments in higher functioning. In the clinical setting and indeed for future research this issue may be circumvented by utilizing 'executively focused' neuropsychological batteries in addition to more commonly used screening test tools [52]. Future studies may consider a meta-analysis design to gain power to further elucidate a relationship between $\mathrm{CI}$ and self-care. 
Table 4 Advice for Clinical Management of Patients with Heart Failure and Cognitive Impairment

Task Sub Task Impairments Recommendations

Understanding and

Monitoring symptoms

Education Programs

Patients with better cognitive function may benefit more from self-management programs than those with worse cognition in the short term [17].

Those with lower educational status may benefit more from programs. Poorly educated subjects may be less skilled with respect to selfmanagement at baseline and hence may have more to learn from such programs [54-56].

Seeking Help

Poor global cognition correlated with worse consulting behaviors [29, 31]. Making decisions to seek help is complex and requires an understanding of HF.

Executive function deficits in $\mathrm{Cl}$ subjects may impair recognition of symptoms and problemsolving hence may delay initiation of selfmanagement as well an inability to recognize who, when or why they need to seek assistance.

HF patients with deficits in IADL, language and attention deficits may not have an ability to engage in communication facilities (e.g. telecommunications, driving to the clinic, making appointments online or by phone) [29]

Adherence to Lifestyle and

Treatment

Managing Other Medical Conditions

General Self-Care Behaviors
Psychological Status

Psychological status has been demonstrated to have an influence on self-care behaviors [47] through patient perceived self-efficacy or indirectly, through effects on memory and executive function [48]. A diagnosis of depression was found to be predictive of lower IADL abilities and self-care management [22, 25].

Personal motivation

Cognitive decline not only diminishes functional abilities, it may dampen the influence of personal factors related to self-care $[9,37]$. These include belief in treatment of the disease, information sources, personal and cultural values that would otherwise influence self-care in a positive manner.

Cognition

Patients who either had impairments in multiple separate domains or global cognition had poor self-care maintenance abilities. These were namely medication adherence, compliance with lifestyle recommendations or requiring assistance with ADLs.

Having a comorbid disease was related to better management and maintenance behaviours [25]. Patients being well versed with and used to self-care practices or, where increasing symptoms or reduced functional capacity may motivate self-care behaviours. Increased burden of comorbidities and symptoms may be detrimental for patients. Increased symptoms burden may limit functional capacity and that could lead to increasing social support.

Self-care confidence that was impaired by poor cognition thus leading to worse self-care behaviours [32].

Self-efficacy and a positive attitude towards disease was important in facilitating appropriate or "expert" self-care behaviours [9].
Clinicians should consider baseline education status to deliver information appropriately as well as ascertain the benefit patients with HF and $\mathrm{Cl}$ may obtain by undertaking selfmanagement programs.

However, several studies have also identified that provision of education, treatment and lifestyle instructions alone are not adequate to uphold appropriate self-care behavior [50, 51],

Clinicians should be aware of the impact of executive function on communication difficulties for persons with $\mathrm{HF}$ and $\mathrm{Cl}$. Cognitive tests geared towards executive function assessment should be utilized.

Clinicians should provide resources for and communication solutions for allow easy access to healthcare for persons with $\mathrm{HF}$ and $\mathrm{Cl}$ Teaching patients select few response options for clinical scenarios may provide a baseline to refer to when a response is required spontaneously

Provision of in-home prompts including wall calendars, blister packs, management flow charts etc.

Where possible provide home visits or an escort to clinical appointments

Establishing an appointment and healthcare support routine that does not vary.

Clinicians may benefit from screening for and appropriately treating depression in patients with heart failure in order to prevent the associated adverse affects it may have on selfcare.

Clinicians should endeavor to convey how health care goals may serve the patient's personally valued goals and priorities in life.

By elucidating the relationship between impairment in specific cognitive domains and self-care as well as identifying factors that may modulate self-care abilities, clinicians may tailor management.

Clinicians should be aware of pre-existing disease which may aid patients who are well versed in self-management or in contrast, may detract from management of concurrent illness or where symptom burden may hinder self-care abilities.

Multidisciplinary and multispecialty input may be required to ensure appropriate management of comorbid conditions.

Clinicians may target confidence through problem solving and experiential learning in HF patients with Cl may improve self-care functions even in the context of cognitive decline [57]. 
A major limitation of the studies reviewed is that assessment of adherence to lifestyle recommendations and answers to the SCHFI were self-reported. Okonkwo and colleagues [53] identified that patients with memory impairments, a domain commonly impaired in HF, tend to over estimate their abilities in completing daily living tasks, which is relevant for two studies which reported adherence to treatment regimens or lifestyle recommendations [19, 21].

Studies with inclusion criteria of $\mathrm{EF}<45 \%$ are better in terms of selecting moderate to severe systolic dysfunction. The others that had a wide range of ejection fraction (including mild and low normal ejection fraction) could have a diluted effect of severity - as it would not be expected that patients with an ejection fraction of $50 \%$ (low normal) would have similar self-management issues or similar re-admission rates for decompensations as those with ejection fraction $30 \%$.

A lack of studies exploring the impairment of specific cognitive domains or dementia subtypes (e.g. vascular, frontotemporal etc) and their involvement in all aspects of self-management makes it difficult to definitively identify the most effective recommendations to manage CI persons with HF.

\section{Implications for health policy}

Persons with $\mathrm{CI}$ and HF require more resources and support in the community to carry out self-care tasks compared to their non-CI counterparts. Primary care and community services should be re-designed to evaluate and cater to individual's self-care needs. The relationship between $\mathrm{CI}$ and self-care ability in HF is quite prominent, however, effectiveness of programs to assist those with $\mathrm{CI}$ and their carers needs to be further elucidated. Programs may have differential benefits based on cognition, support and demographic factors so these need to be further characterized to improve management and outcomes for these persons in the community. Table 4 outlines advice generated for clinical use.

\section{Generalizability}

The aforementioned findings may be applied widely at the patient level as demographic characteristics of subjects were largely similar where impairments in cognitive domains were not based on geography or ethnicity. The present review includes articles spanning twelve years (2005-2016), therefore assessment and interpretations of $\mathrm{CI}$, as well as the diagnostic criteria for dementia/CI may have varied across time.

\section{Conclusion}

Managing persons with $\mathrm{HF}$ and $\mathrm{CI}$ is particularly difficult. Decrements in cognitive domains adversely impacts self care abilities of these individuals, ultimately leading to poor outcomes. Clinicians need to be aware of the differential impacts of impairments in cognitive domains and tailor their management accordingly. Regular screening tests for higher order functions along with those for global cognitive function in the older patients with HF are necessary if optimum self-care is to be supported. Awareness of other factors such as depression, self-confidence and access to supports may also modulate self-care ability. A holistic, multifactorial approach is required to improve outcomes in this particularly vulnerable population with $\mathrm{HF}$ and $\mathrm{CI}$.

\section{Additional file}

Additional file 1: Table S1. DSM V Criteria for Diagnosing Major \& Minor Neurocognitive Disorder (NCD)*. Table S2. Search terms used for literature search. Table S3. Conversion of scales reporting severity of comorbid conditions [58-60]. Figure S1. PRISMA flow diagram of identification, screening, and inclusion of eligible articles. (DOCX 49 kb)

\section{Abbreviations}

ADLs: Activities of daily living; Cl: Cognitive impairment; DSST: Digit symbol substitution test; EHFScB-9: European heart failure self-care behaviour scale; HF: Heart failure; IADLs: Independent activities of daily living; KCCQ: Kansas City cardiomyopathy questionnaire; K-MMSE: Korean version mini mental state examination; LVEF: Left ventricular ejection fraction; MMSE: Mini mental state examination; MoCA: Montreal cognitive assessment; NYHA: New York heart association; SCHFI: Self Care of Heart Failure Index; SLUMS: St. Louis University mental status exam

Acknowledgments

Not applicable.

\section{Funding}

Internal departmental funds. The funding body had no influence on design of the study, data collection, analysis, interpretation of data and in writing of the manuscript.

\section{Availability of data and materials}

All data generated or analyzed during this study are included in this published article and its supplementary information files.

\section{Authors' contributions}

All authors listed have contributed sufficiently to the project to be included as authors as outlined by the International Committee of Medical Journal Editors and all those who are qualified as authors are listed in the author byline. Specific contributions from individual authors: JL (Lead Author): Development of concept and design of the work, acquisition of the work, analysis, interpretation of data, drafting the work and revising it critically for important intellectual content, final approval of the version to be published, agreement to be accountable for all aspects of the work in ensuring that questions related to the accuracy or integrity of any part of the work are appropriately investigated and resolved. TP: Analysis, interpretation of data, drafting the work and revising it critically for important intellectual content, final approval of the version to be published, agreement to be accountable for all aspects of the work in ensuring that questions related to the accuracy or integrity of any part of the work are appropriately investigated and resolved. SN: Analysis, interpretation of data, drafting the work and revising it critically for important intellectual content, final approval of the version to be published, agreement to be accountable for all aspects of the work in ensuring that questions related to the accuracy or integrity of any part of the work are appropriately investigated and resolved. MD: Analysis, interpretation of data, drafting the work and revising it critically for important intellectual content, final approval of the version to be published, agreement to be accountable for all aspects of the work in ensuring that questions related to the accuracy or integrity of any part of the work are 
appropriately investigated and resolved. MJ: Analysis, interpretation of data, drafting the work and revising it critically for important intellectual content, final approval of the version to be published, agreement to be accountable for all aspects of the work in ensuring that questions related to the accuracy or integrity of any part of the work are appropriately investigated and resolved. JEl: Development of concept and design of the work, acquisition of the work, analysis, interpretation of data, drafting the work and revising it critically for important intellectual content, final approval of the version to be published, agreement to be accountable for all aspects of the work in ensuring that questions related to the accuracy or integrity of any part of the work are appropriately investigated and resolved. All authors read and approved the final manuscript.

\section{Ethics approval and consent to participate}

Not applicable.

\section{Consent for publication}

Not applicable.

\section{Competing interests}

Janaka Lovell, Tony Pham, Samer Noaman, Marie-Claire Davis, Marilyn Johnson and Joseph Ibrahim have no potential financial, corporate, commercial or personal interests that may constitute a source of bias.

\section{Publisher's Note}

Springer Nature remains neutral with regard to jurisdictional claims in published maps and institutional affiliations.

\section{Author details}

${ }^{1}$ Department of Forensic Medicine, Monash University, 65 Kavanagh Street, Southbank, Victoria 3006, Australia. 'Department of Cardiology, Alfred Health, Victoria 3004, Australia. ${ }^{3}$ Calvary Health Care Bethlehem, Victoria 3162, Australia. ${ }^{4}$ Institute of Transport Studies, Monash University, Victoria 3800, Australia.

Received: 3 December 2018 Accepted: 11 April 2019

\section{Published online: 29 April 2019}

\section{References}

1. Jessup M, Abraham W, Casey D, Casey DE, Feldman AM, Francis GS, et al. Focused update: ACCF/AHA guidelines for the diagnosis and management of heart failure in adults: a report of the American College of Cardiology Foundation/American Heart Association task force on practice guidelines. Circulation. 2009;119(14):1977-2016

2. Mozzafarian D, Benjamin EJ, Go AS, Arnett DK, Blaha MJ, Cushman M, et al, Heart disease and stroke statistics - 2016 update: a report from the American Heart Association. Circulation. 2016:133:e38-e360.

3. McMurray JJ, Adamopoulos S, Anker SD, Auricchio A, Bohm M, Dickstein K et al. ESC guidelines for the diagnosis and treatment of acute and chronic heart failure 2012: the task force for the diagnosis and treatment of acute and chronic heart failure 2012 of the european society of cardiology. Eur Heart J. 2012;33(14):1787-847.

4. Heidenreich PA, Albert NM, Allen LA, Bluemke DA, Butler J, Fonarow GC, et al. Forecasting the impact of heart failure in the United States: a policy statement from the american heart association. Circ Heart Fail. 2013;6(3): 606-19.

5. Alzheimer's Disease International [Internet]. United Kingdom: The global voice on dementia; c2016 [cited 2016 Dec 22]. Available from:https://www. alz.co.uk/research/statistics.

6. Currie K, Rideout A, Lindsay G, Harkness K. The association between mild cognitive impairment and self-care in adults with chronic heart failure. J Cardiovasc Nurs. 2015;30(5):382-93.

7. White MF, Kirschner J, Hamilton MA. Self-care guide for the heart failure patient. Circulation. 2014;129(3):e293-4.

8. Cameron J, Rendell PG, Ski CF, Kure CE, McLennan SN, Rose NS, et al. PROspective MEmory training to improve HEart failUre self-care (PROMETHEUS): study protocol for a randomised controlled trial. Trials. 2015; 16(196):196

9. Dickson WD, Deatrick JA, Riegal B. A typology of heart failure self-care management in non-elders. Eur J Cardiovasc Nurs. 2008;7(3):171-81.
10. Alves TC, Rays J, Fraguas R, Wajngarten M, Meneghetti JC, Prando S, et al. Localized cerebral blood flow reductions in patients with heart failure: a study using 99mTc-HMPAO SPECT. J Neuroimaging. 2005;15(2):150-6.

11. Jovicic A, Holroyd-Leduc JM, Straus SE. Effects of self-management intervention on health outcomes of patients with heart failure: a systematic review of randomized controlled trials. BMC Cardiovasc Disord. 2006:6:43.

12. Moher D, Shamseer L, Clarke M, Ghersi D, Liberati A, Petticrew M, et al. Preferred reporting items for systematic review and meta-analysis protocols (PRISMA-P) 2015 statement. Syst Rev. 2015;4(1):1.

13. DSM American Psychiatric Association. Neurocognitive disorder, diagnostic and statistical manual of mental disorders. 5th ed. Washington DC: American Psychiatric Publishing; 2013.

14. Lorig KR, Holman H. Self-management education: history, definition, outcomes and mechanisms. Ann behave Med. 2003;26(1):1-7.

15. Riegel B. Self care of heart failure index V6.2 English [Internet] Philadelphia: Biobehavioural Research Center, School of Nursing, Claire M. Fagin Hall; c2016 [cited 2016 Dec 12]. Available from: http://selfcare-measures.com/wp-content/uploads/2018/04/SCHFI_R6.2_revised_309.pdf.

16. Karlsson MR, Edner M, Henriksson P, Mejhert M, Persson H, Grut M, et al. A nurse-based management program in heart failure patients affects females and persons with cognitive dysfunction most. Patient Educ Couns. 2005; 58(2): 146-53.

17. Smeulders ES, Van Haastregt JC, Ambergen T, Stoffers HE, Janssen-Boyne JJ, Uszko-Lencer NH. Heart failure patients with a lower educational level and better cognitive status benefit most from a self-management group programme. Patient Educ Couns. 2010;81(2):214-21.

18. Habota T, McLennan SN, Cameron J, Henry JD, Ski CF, Thompson DR, et al. Prospective memory impairment in chronic heart failure. J Int Neuropsychol Soc. 2015;21(3):183-92

19. Alosco ML, Spitznagel MB, Van Dulmen M, Raz N, Cohen R, Sweet LH, et al. Cognitive function and treatment adherence in older adults with heart failure. Psychosom Med. 2012;74(9):965-73.

20. Hawkins LA, Kilian S, Firek A, Kashner TM, Firek CJ, Silvet $H$, et al. Cognitive impairment and medication adherence in outpatients with heart failure. Heart Lung. 2012:41(6):572-82.

21. Alosco ML, Spitznagel MB, Cohen R, Sweet LH, Colbert LH, Josephson R, et al. Cognitive impairment is independently associated with reduced instrumental activities of daily living in persons with heart failure. $J$ Cardiovasc Nurs. 2012;27(1):44-50.

22. Alosco ML, Spitznagel MB, Raz N, Cohen R, Sweet LH, Colbert LH, et al. Executive dysfunction is independently associated with reduced functional independence in heart failure. J Clin Nurs. 2014:23(5-6):829-36.

23. Hajduk AM, Lemon SC, McManus DD, Lessard DM, Gurwitz JH, Spencer FA, et al. Cognitive impairment and self-care in heart failure. Clin Epidemiol. 2013;5(1):407-16.

24. Hjelm CM, Brostrom A, Riegel B, Arestedt K, Stromber A. The association between cognitive function and self-care in patients with chronic heart failure. Heart Lung. 2015:44(2):113-9.

25. Cameron J, Worrall-Carter L, Riegel B, Lo SK, Stewart S. Testing a model of patient characteristics, psychologic status, and cognitive function as predictors of self-care in persons with chronic heart failure. Heart Lung. 2009:38(5):410-8.

26. Cameron J, Worrall-Carter L, Page K, Riegel B, Lo SK, Stewart S. Does cognitive impairment predict poor self-care in patients with heart failure? Eur J Heart Fail. 2010;12(5):508-15.

27. Davis KK, Himmelfarb CR, Szanton SL, Hayat MJ, Allen JK. Predictors of heart failure self-care in patients who screened positive for mild cognitive impairment. J Cardiovasc Nurs. 2015;30(2):152-60.

28. Davis KK, Mintzer M, Dinnison Himmelfarb CR, Hayat MJ, Rotman S, Allen J. Targeted intervention improves knowledge but not self-care or readmissions in heart failure patients with mild cognitive impairment. Eur J Heart Fail. 2012;14(9):1041-9.

29. Harkness KH, Heckman GA, Akhtar-Danesh N, Demers C, Gunn E, McKelvie RS. Cognitive function and self-care management in older patients with heart failure. Eur J Cardiovasc Nurs. 2014;13(3):277-84.

30. Kim JS, Hwang SY, Shim JL, Jeong MH. Cognitive function and self-care in patients with chronic heart failure. Korean Circ J. 2015;45(4):310-6.

31. Lee CS, Gelow JM, Bidwell JT, Mudd J, Green JK, Jurgens CY, et al. Blunted responses to heart failure symptoms in adults with mild cognitive dysfunction. J Cardiovasc Nurs. 2013;28(6):534-40. 
32. Vellone EF, Fida R, D'Agostino F, Mottola A, Juarez-Vela R, Alvaro R, et al. Self-care confidence may be the key: a cross-sectional study on the association between cognition and self-care behaviors in adults with heart failure. Int J Nurs Stud. 2015:52(11):1705-13.

33. Habota T, Cameron J, McLennan SN, Ski CF, Thompson DR, Rendell PG. Prospective memory and chronic heart failure. BMC Cardiovasc Disord. 2013; 13(63).

34. Swendeman D, Ingram BL, Rotheram-Borus MJ. Common elements in selfmanagement of HIV and other chronic illnesses: an integrative framework. AIDS Care. 2009;21(10):1321-34

35. Cramm J, Hartgerink JM, Steyerberg E, Bakker TJ, Mackenbach JP, Nieboer AP. Understanding older patients' self-management abilities: functional loss, self- management, and wellbeing. Qual Life Res. 2013;22(1):85-92.

36. Aggarwal B, Liao M, Allegrante JP, Mosca L. Low social support level is associated with non-adherence to diet at 1 year in the family intervention trial for heart health (FIT heart). J Nutr Educ Behav. 2010;42(6):380-8

37. Hicks FD, Holm K. Self-management decision influences in heart failure. Clin Nurs Res. 2003;12(1):69-84.

38. Dal Negro RW, Bonadiman L, Bricolo FP, Tognella S, Turco P. Cognitive dysfunction in severe chronic obstructive pulmonary disease (COPD) with or without long-term oxygen therapy (LTOT). Multidiscip Respir Med. 2015; $10(1): 17$

39. Alosco ML, Spitznagel MB, Josephson R, Hughes J, Gunstad J. COPD is associated with cognitive dysfunction and poor physical fitness in heart failure. Heart Lung. 2015:44(1):21-6.

40. Thornton WL, Shapiro RJ, Deria S, Gelb S, Hill A. Differential impact of age on verbal memory and executive functioning in chronic kidney disease. J Int Neuropsychol Soc. 2007;13(2):344-53.

41. Riley PL, Arslanian-Engoren C. Cognitive dysfunction and self-care decision making in chronic heart failure: a review of the literature. Eur J Cardiovasc Nurs. 2013;12(6):505-11.

42. Stilley CS, Bender CM, Dunbar-Jacob J, Sereika S, Ryan CM. The impact of cognitive function on medication management: three studies. Health Psychol. 2010;29(1):50-5.

43. Lezak MD, Howieson DB, Bigler ED, Tranel D. Neuropsychological assessment. 5th ed. New York: Oxford University Press; 1995.

44. Dickson W, Tkacs N, Riegel B. Cognitive influences on self-care decision making in persons with heart failure. Am Heart J. 2007;154(3):424-31.

45. Pressler SJ, Kim J, Riley P, Ronis DL, Gradus-Pizlo I. Memory dysfunction, psychomotor slowing, and decreased executive function predict mortality in patients with heart failure and low ejection fraction. J Card Fail. 2010; 16(9):750-60.

46. Reeder KM, Ercole PM, Peek GM, Smith CE. Symptom perceptions and selfcare behaviors in patients who self-manage heart failure. J Cardiovasc Nurs. 2015;30(1):E1-7.

47. Connelly CE. An empirical study of a model of self-care in chronic illness. Clin Nurse Spec. 1993;7(5):247-53.

48. Butters MA, Whyte EM, Nebes RD, Begley AE, Dew MA, Mulsant BH, et al. The nature and determinants of neuropsychological functioning in late-life depression. Arch Gen Psychiatry. 2004;61 (6):587-95.

49. Cacciatore F, Abete P, Ferrara N, Calabrese C, Napoli C, Maggi S, et al. Congestive heart failure and cognitive impairment in an older population. Osservatorio geriatrico campano study group. J Am Geriatr Soc. 1998;46(11): 1343-8.

50. Evangelista L, Doering LV, Dracup K, Westlake C, Hamilton M, Fonarow GC Compliance behaviors of elderly patients with advanced heart failure. J Cardiovasc Nurs. 2003;18(3):197-206.

51. Ni H, Nauman D, Burgess D, Wise K, Crispell K, Hershberger RE. Factors influencing knowledge of and adherence to self-care among patients with heart failure. Arch Intern Med. 1999;159(14):1613-9.

52. Nakata E, Kasai M, Kasuya M, Akanuma K, Meguro M, Ishii H, et al. Combined memory and executive function tests can screen mild cognitive impairment and converters to dementia in a community: the osaki-tajiri project. Neuroepidemiology. 2009;33(2):103-10.

53. Okonkwo OC, Wadley VG, Griffith HR, Griffith HR, Belue K, Lanza S, et al. Awareness of deficits in financial abilities in patients with mild cognitive impairment: going beyond self-informant discrepancy. Am J Geriatr Psychiatry. 2008;16(8):650-9.

54. Philbin EF, Dec GW, Jenkins PL, DiSalvo TG. Socioeconomic status as an independent risk factor for hospital readmission for heart failure. Am J Cardiol. 2001;87(12):1367-71.
55. Rathore SS, Masoudi FA, Wang Y, Curtis JP, Foody JM, Havranek EP, et al. Socioeconomic status, treatment, and outcomes among elderly patients hospitalized with heart failure: findings from the national heart failure project. Am Heart J. 2006;152(2):371-8.

56. Sui X, Gheorghiade M, Zannad F, Young JB, Ahmed A. A propensity matched study of the association of education and outcomes in chronic heart failure. Int J Cardiol. 2008;129(1):93-9.

57. Fenter PC. Understanding the role of practice in learning for geriatric individuals. Top Geriatr Rehabil. 2002;17(4):11-32.

58. Quan H, Li B, Couris CM, Fushimi K, Graham P, Hider P, et al. Updating and validating the charlson comorbidity index and score for risk adjustment in hospital discharge abstracts using data from 6 countries. Am J Epidemiol. 2011;173(6):676-82.

59. Hirdes JP, Frijters DH, Teare GF. The MDS-CHESS scale: a new measure to predict mortality in institutionalized older people. J Am Geriatr Soc. 2003; 51(1):96-100.

60. Haas LR, Takahashi PY, Shah ND, Stroebel RJ, Bernard ME, Finnie DM, et al. Risk-stratification methods for identifying patients for care coordination. Am J Manag Care. 2013;19(9):725-32

\section{Ready to submit your research? Choose BMC and benefit from:}

- fast, convenient online submission

- thorough peer review by experienced researchers in your field

- rapid publication on acceptance

- support for research data, including large and complex data types

- gold Open Access which fosters wider collaboration and increased citations

- maximum visibility for your research: over $100 \mathrm{M}$ website views per year

At $\mathrm{BMC}$, research is always in progress.

Learn more biomedcentral.com/submissions 